\title{
Structural Characterization of Broad Oxide Layers of Ag Single Crystals Caused by Hyperthermal Atomic Oxygen by SEM and TEM
}

\author{
Long Li and Judith C. Yang
}

Department of Materials Science and Engineering, 848 Benedum Hall, University of Pittsburgh, Pittsburgh, PA 15261, USA.

Hyperthermal atomic oxygen (AO) is the major species in the Low Earth Orbit (LEO), defined as approximately 200 to 500 miles above the earth, hastening failure to materials exposed in this harsh environment [1]. Silver is used in a wide variety of applications in LEO, such as electron conductive material [2] as well as a detector or sensor material for calibrating atomic oxygen exposure [3-5]. We focused on the morphology changes on a model metal material, Ag, when exposed to hyperthermal atomic oxygen in order to gain insights into degradation mechanisms in Low Earth Orbit.

We exposed both $\mathrm{Ag}(100)$ and $\mathrm{Ag}(111)$ single crystals to an atomic oxygen source with 50,000 shots at $220{ }^{\circ} \mathrm{C}$ simultaneously, where the $5 \mathrm{eV}$ atomic oxygen was created by the detonation of oxygen gas with a pulsed laser. The oxide surfaces were protected by gluing a silicon wafer on each to prepare samples for observations of cross-section SEM (XSEM) and cross-section TEM (XTEM). SEM images reveal the morphology of $\mathrm{AO}$ oxidation of $\mathrm{Ag}(100)$ and $\mathrm{Ag}(111)$ with very rough surfaces on Figure 1 (a) and (b), with mud-like cracks on $\mathrm{Ag}(100)$ and cracks on $\mathrm{Ag}(111)$, respectively. Figures 1 (c) and (d) are XSEM images of oxide layers of $\mathrm{Ag}(100)$ and $\mathrm{Ag}(111)$, which reveal a very thick oxide scale with multiple oxide layers containing elongated, large pores. The $\operatorname{Ag}(100)$ oxide scale has an average thickness of 11.6 microns and the $\operatorname{Ag}(111)$ oxide scale forms a thicker oxide scale of 14.9 microns. The detached oxide from the Ag demonstrates a very weak bond between crystal silver substrate and its oxide film. Figures 2 (a) and (b) are XTEM images of Ag (100) oxide layer. Figure 2(a) shows the broad intact interface of $\mathrm{Ag}(100)$ and the oxide layer. The inset electron diffraction pattern (EDP) shows a single crystalline silver of the substrate and a complex poly-crystalline oxide layer. Figure 2(b) reveals the complex microstructures of the oxide layer, such as porosity, micro-twins and irregular shaped grains. The inset EDP shows the polycrystalline structure of oxide layer. Figure 2 (c) is a XTEM image of $\operatorname{Ag}(111)$ oxide layer, showing the broad and detached interface. Figure 2(d) is high-mag TEM image of the interface of $\operatorname{Ag}(111)$ and the oxide layer, showing the nano-crystallites of xides in $10 \sim 40 \mathrm{~nm}$ near interface area.

We would like to thank Prof. Timothy K. Minton for the AO exposure, and Dr.Vania Petrova, Dr.Ray Twesten and Dr.Mauro Sardela, for their assistance. The characterization was performed in the Center for Microanalysis of Materials, University of Illinois at Urbana-Champaign, which is partially supported by the U.S. Department of Energy under grant DEFG02-96-ER45439. This project is the Multi-University Research Initiative (MURI) supported by Air Force Office of Scientific Research. 


\section{References}

[1] A.E. Hedin and J. Geophys. Res. 92(5), 4649 (1987).

[2] M.K. Bhan, P.K. Nag, G.P. Miller and J.C. Gregory, J. Vac. Sci. Technol. A, 12(3), 699(1994).

[3] A.R. Chambers, I.L. Harris and G.T. Roberts, Mater. Lett. 26, 121(1996).

[4] I.L. Harris, A.R. Chambers and G.T. Roberts, Mater. Lett. 31, 321(1997).

[5] L. Li and J. C. Yang, Microscopy of Oxidation 5, in press.

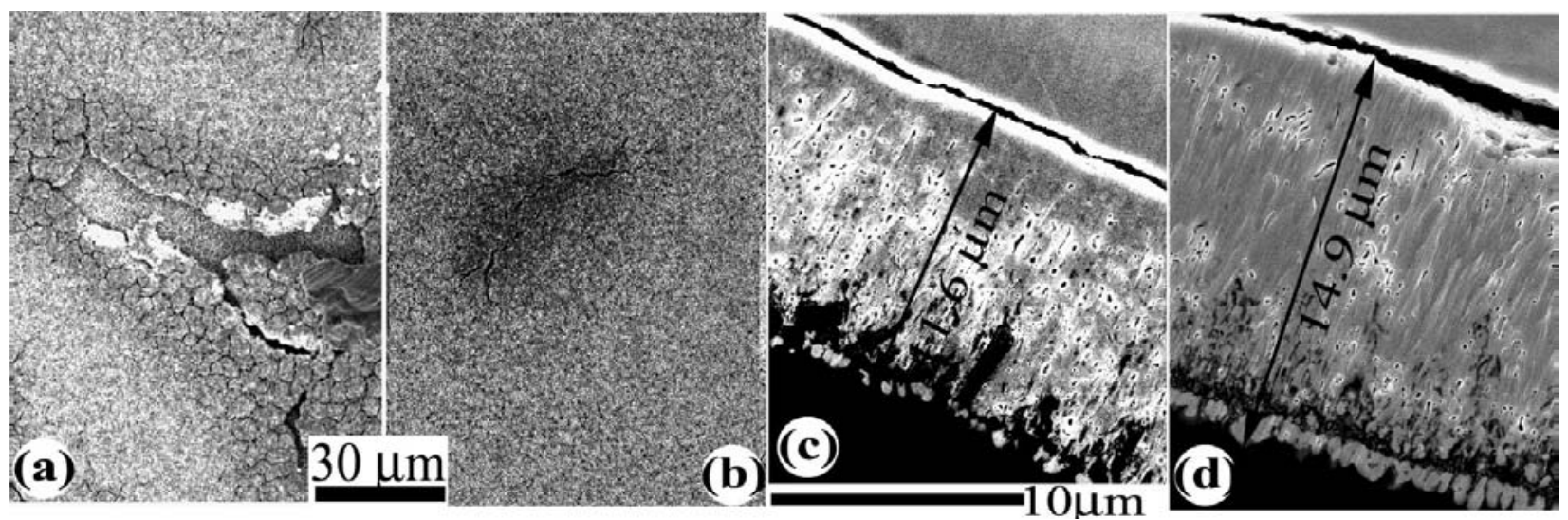

Figure 1. SEM images of: (a) oxide scale of $\operatorname{Ag}(100)$, (b) oxide scale of $\operatorname{Ag}(111)$, (c) crosssection of $\operatorname{Ag}(100)$ and (d) cross-section of $\operatorname{Ag}(111)$, respectively.

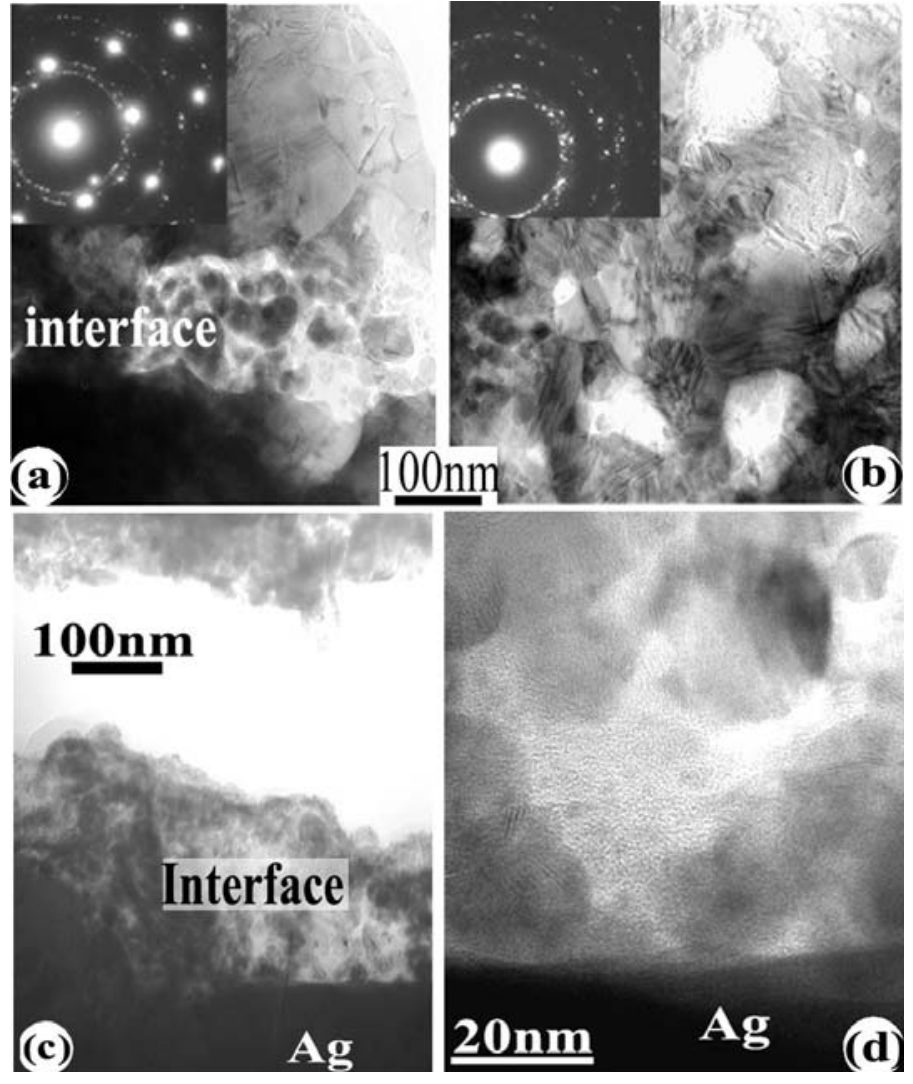

Figure 2. Cross- section TEM images: (a) broad intact interface and (b) the oxide scale of $\operatorname{Ag}(100)$ oxide layer, both with inset corresponding EDP, (c) broad, detached interface of $\operatorname{Ag}(111)$ oxide layer, and (d) high-magnification image of $\mathrm{Ag}(111)$ interface, showing silver oxide crystallites at interface area. 